\title{
The Zoning of Forest Fire Potential of Gulestan Province Forests Using Granular Computing and MODIS Images
}

\author{
A.Jalilzadeh Shadlouei ${ }^{\text {a, }}$, M.R.Delavar ${ }^{\text {a }}$ \\ ${ }^{a}$ GIS Division, Dept. of Geomatics Engineering, Faculty of Engineering, University of Tehran, Tehran, Amirabad \\ avenue, a.jalilzadeh@ut.ac.ir, mdelavar@ut.ac.ir
}

KEY WORDS: Forest Fires, Zoning, Granular Computing, Geospataial Information System, Remote Sensing.

\begin{abstract}
:
There are many vegetation in Iran. This is because of extent of Iran and its width. One of these vegetation is forest vegetation most prevalent in Northern provinces named Guilan, Mazandaran, Gulestan, Ardebil as well as East Azerbaijan. These forests are always threatened by natural forest fires so much so that there have been reports of tens of fires in recent years. Forest fires are one of the major environmental as well as economic, social and security concerns in the world causing much damages. According to climatology, forest fires are one of the important factors in the formation and dispersion of vegetation. Also, regarding the environment, forest fires cause the emission of considerable amounts of greenhouse gases, smoke and dust into the atmosphere which in turn causes the earth temperature to rise up and are unhealthy to humans, animals and vegetation. In agriculture droughts are the usual side effects of these fires. The causes of forest fires could be categorized as either Human or Natural Causes. Naturally, it is impossible to completely contain forest fires; however, areas with high potentials of fire could be designated and analysed to decrease the risk of fires. The zoning of forest fire potential is a multi-criteria problem always accompanied by inherent uncertainty like other multi-criteria problems. So far, various methods and algorithm for zoning hazardous areas via Remote Sensing (RS) and Geospatial Information System (GIS) have been offered. This paper aims at zoning forest fire potential of Gulestan Province of Iran forests utilizing Remote Sensing, Geospatial Information System, meteorological data, MODIS images and granular computing method. Granular computing is part of granular mathematical and one way of solving multi-criteria problems such forest fire potential zoning supervised by one expert or some experts, and it offers rules for classification with the least inconsistencies. On the basis of the experts' opinion, 6 determinative criterias contributing to forest fires have been designated as follows: vegetation (NDVI), slope, aspect, temperature, humidity and proximity to roadways. By applying these variables on several tentatively selected areas and formation information tables and producing granular decision tree and extraction of rules, the zoning rules (for the areas in question) were extracted. According to them the zoning of the entire area has been conducted. The zoned areas have been classified into 5 categories: high hazard, medium hazard (high), medium hazard (low), low hazard (high), low hazard (low). According to the map, the zoning of most of the areas fall into the low hazard (high) class while the least number of areas have been classified as low hazard (low). Comparing the forest fires in these regions in 2010 with the MODIS data base for forest fires, it is concluded that areas with high hazards of forest fire have been classified with a 64 percent precision. In other word 64 percent of pixels that are in high hazard classification are classified according to MODIS data base. Using this method we obtain a good range of Perception. Manager will reduce forest fire concern using precautionary proceeding on hazardous area
\end{abstract}

\section{INTRODUCION}

As mentioned, one of the problem and issue are concerned by manager and administrator is forest fire that could result on irreparable damages, so accurate, on time and developing mapping from damaged and fired forest and areas with high potential of fire is necessary. For this kind of mapping, Remote Sensing (RS) technique and satellite imagery is the most usual way used nowadays. Satellite imagery can provide temporal and locational maps for studying of natural events at low cost and in different times and different locations. Moreover information resulted from satellite data analyses can be used easily in Geospatial Information System (GIS) and allow us store large amount of data's and retrieve them. Because of humid weather and proximity to Caspian Sea, north of Iran has forest vegetation that is always exposed to fire. Tens of fires has been occurred in recent years.

\subsection{Literature Review}

So far different techniques and methods has been used for prediction of forest fire potential area and different measure has been taken for prohibiting of it. The first use of RS was in 1960 when infrared sensors were used for recognition of fired area. In 1970 spectral sensors were used then LANDSAT sensors were used for burned vegetation and damaged area. In recent years Wenliang Liu and associates combined GIS and RS for

\footnotetext{
*A.Jalilzadeh Shadlouei

e-mail: a.jalilzadeh@ut.ac.ir

Phone: +989371755472
} 
analysisof forest fire potential areas. In 2009 K.D Varden analysed forest fire areas by using of Multi-Criteria methods.

\subsection{Zoning Algorithm}

Different methods and algorithms can model zoning maps but most of them aren't useful for entire forest areas over the earth and are practical for only some special areas. Moreover zoning of forest fire area is a Multi-Criteria problem that is based on experts opinions an usually accompanied by some uncertainty. Uncertainty is because of different factors such as incompatibility in experts opinions, lack of certainty of experts on all sides of issue and large volume of data that are used for analysis. Granular computing is one of the methods introduced for overcome all of issues mentioned above. This method extracts rules based on 2 important principals: 1- Instruction of Granules 2- Relations between Granules. One of important features of granular computing is extracting of rules that have lowest incompatibility or zero incompatibility by using training data's. Furthermore the rules don't have overlaps. Granular computing is a collection of theories, methodologies, technique and tools for instruction of granules, groups and classification of reference set used for resolving problems. Resolving problems using granular computing has developed in many knowledge such as Interval Analysis, Rough Set Theory, Fuzzy Set and Clustering. First time Granular Computing introduced by Zadeh in 1979. A concept in granular computing has 2 aspect: 1- Intention 2- Extension. Intention is all the notions and criterias that explain a concept and extension is all the objects that are samples for concept. At this problem all the criteria and causes of fire are concerned as intentions and all the area that are potent to fire are extensions

\section{2- GRANULAR COMPUTING}

In this study, granular computing is used for extraction of classification rules that is an example of rule extraction. Spatial database model is described as a collection of objects by a limited set of characteristic. The rules is used for describing of the relationship between objects and different measurement is done for assessment of precision, accuracy and consistency.

\subsection{Basic concepts of Granular Computing}

A granular can be considered as a part of several parts with other component make up big units. Granulation is dividing of reference set to parts or group or classes based on available information and classification rules. At least three structure is proposed to describing of granular; Internal structure of a granular, the cumulative structure of a granular set, hierarchical structure of a granular network

Granulation of Reference Set: Granulation is dividing of reference set to subsets or groups or parts based on classification rules and formulas.

\subsection{Granular Computing Model for Extracting of Classification Rules}

Information Table: Information table describes a set of objects which in each row of this table is located an object and in its columns are located attributes and classes. Each cell of this table represents a qualitative value of a $\mathrm{n}$ attribute to one special object and described as follow:

$$
\mathrm{S}=(\mathrm{U}, \mathrm{At}, \mathrm{EL},\{\mathrm{va} \mid \mathrm{a} \in \mathrm{A}\},\{\mathrm{a} \mid \mathrm{a} \in \mathrm{A}\})
$$
where $U$ is a non-empty set of objects
At is a non-empty set of attribute
$\mathrm{L}$ is al language feature of At
$\mathrm{Va}$ is a set of values for attribute set
and $\quad F a$ is a function that for every $x \in U$ and every a $\in$ At result on $f(x, a) \in V a$

all the necessary information and data is represented in information table. An formula of $\varphi$ is described by the value of $\mathrm{x} \in \mathrm{U}$ and $\mathrm{a} \in \mathrm{At}$. If $\varphi$ is a formule, the granule of $\operatorname{Ms}(\varphi)$ will define as:

$\operatorname{Ms}(\varphi)=\{x|x \in U, x=| \varphi\}$
$x=\mid \varphi$

where the formula 3 means that object of $\mathrm{x}$ is adapted to formula $\varphi$ so Ms is all the objects that adapted to formula $\varphi$. All these object construct an granule. The type of granulation depends on way of problem solving. In classification irredundancy must be considered. A subset of reference set is considered as redundant if it is deleted, the remaining subset cover the set thoroughly. An a subset $x$ of reference set will be a granule if there is a formula of $\varphi$ that $\operatorname{Ms}(\varphi)=\mathrm{x}$

Measures of a single granule (generality): Generality indicates the relative size of the granule. A granule defined by the formula is more general if it covers more instances of the universe. The quantity may be viewed as the probability of a randomly selected object satisfying the formula

$$
\mathrm{G}(\varphi)=\frac{|m(\varphi)|}{|U|}
$$

where

$|m(\varphi)|$ is the number of elements within the the granule $\mathrm{G}(\varphi)$ is the probability of a granule

and $|U|$ is the total number of reference set

Measurements on relationship between granules:

Confidence or absolute support: This is defined as the fraction of instances that are correctly classified by the rule among the instances for which it makes any prediction

$$
\operatorname{As}(\varphi \Rightarrow \psi)=\frac{|m(\varphi \cap \psi)|}{|m(\varphi)|}
$$

where $|m(\varphi \cap \psi)|$ is the number of common elements between class $\psi$ and formula $\varphi$

Coverage: This is a measure of the applicability or recall of the inference. It indicates fraction of data in a class correctly classified by the rule 
$\mathrm{CV}(\varphi \Rightarrow \psi)=\frac{|m(\varphi \cap \psi)|}{|m(\psi)|}$

Conditional entropy: It provides a measure that is inversely related to the strength of the inference. This measurement which depends on the confidence is a most commonly used measure for selecting an attribute value in the construction of decision tree for classification:

$\mathrm{H}(\psi \mid \varphi)=-\sum_{i=1}^{i=n} P\left(\psi_{\mathrm{i}} \mid \varphi\right) * \log \mathrm{P}\left(\psi_{\mathrm{i}} \mid \varphi\right)$

where the base of logarithm is 2

Accuracy of Classification: In order to a final measure of accuracy and uncertainty, the accuracy of classification is used:

$\mathrm{k} /(\mathrm{k}+\mathrm{n})$

where $\mathrm{k}$ is number of objects that classified truly by formula $\varphi$ and $\mathrm{n}$ is the number of objects that don't classified truly.

\section{METHODOLOGY OF RESEARCH, CASE STUDY AND FOREST FIRE ZONING}

\subsection{Methodology of research}

\subsection{Study area and decision criteria}

In this research, the study area is Gulestan Forest located at the north of Iran at latitude of $36^{\circ} 20^{\prime}$ to $38^{\circ} 00^{\prime}$ and longitude of $54^{\circ} 30^{\prime}$ to $56^{\circ} 20^{\prime}$ in the area of $20381 \mathrm{~km}^{2}$. Tens of fires occur there each year. Based on experts opinions 6 criteria has been determined that are vegetation, slope, moisture, temperature, aspect and proximity to roads so the data of MODIS imagery (MOD13Q1, MOD14A2) in 2010, digital elevation model of SRTM in 2010 and aerological data has been analysed for this problem. Softwares of ENVI 4.8, ArcGIS 10, MATLAB 2010 and Expert Choice1 also used for analysis of data and outputs. Normalized Difference Vegetation Index as an index for vegetation has been resulted from MODIS image on $1^{\text {st }}$ July 2010 with the spatial resolution of $250 \mathrm{~m}$ and the period of 16 . Moisture and temperature is recorded in local aerological station and slope and aspect calculated from Digital Elevation Model (DEM) of SRTM and the roads extracted from road map of Gulestan province.

For resolving this multi-criteria problem, 100 pixels are considered as training data based on experts opinions and the rules extracted from these data. MODIS images used for analysing of extracted rules. At first, information table of training data is formed. This table has 100 columns (the number of training data) and 7 rows (the number of criteria, and the class that each pixel has arranged on it based on experts opinions). The value of each criteria is text, in other word the numerical value of each criteria has been divided to some interval and labelled by text language. Because of large value of training data we show information table just for 10 pixels (Table1).

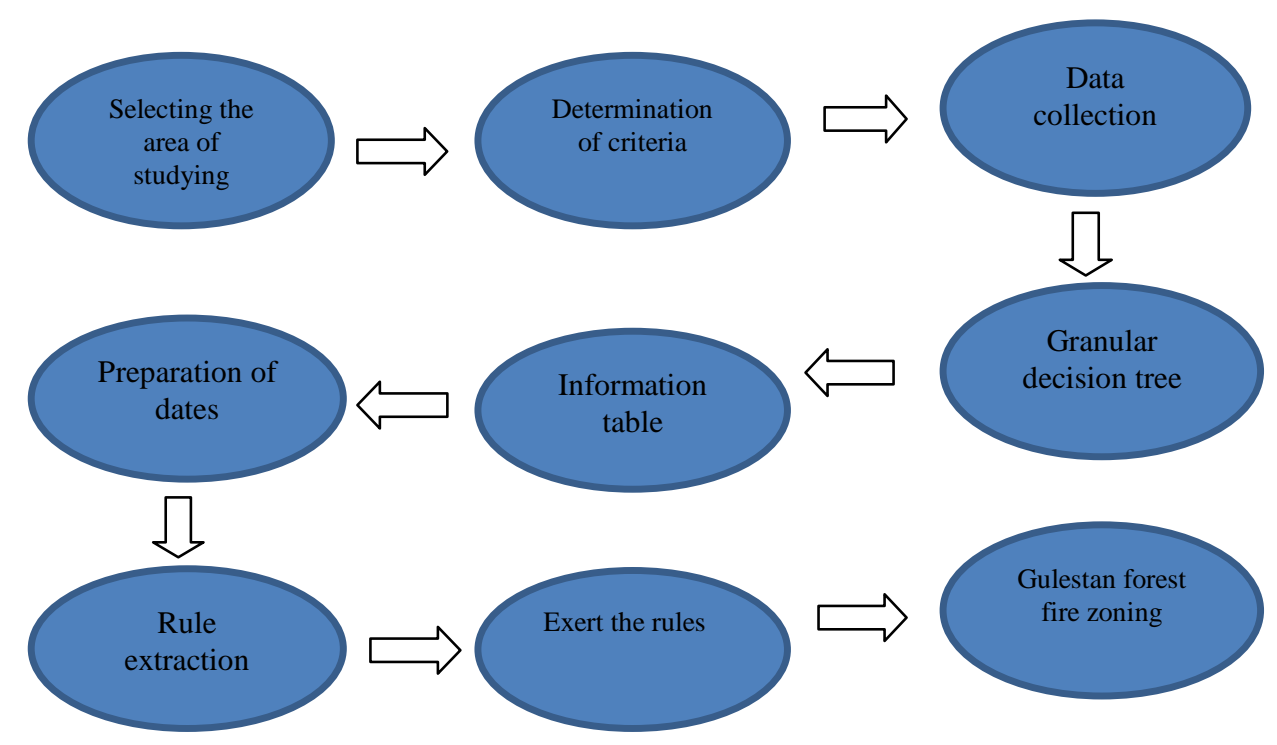

Figure 1. Methodology of Research 
International Archives of the Photogrammetry, Remote Sensing and Spatial Information Sciences, Volume XL-1/W3, 2013 SMPR 2013, 5 - 8 October 2013, Tehran, Iran

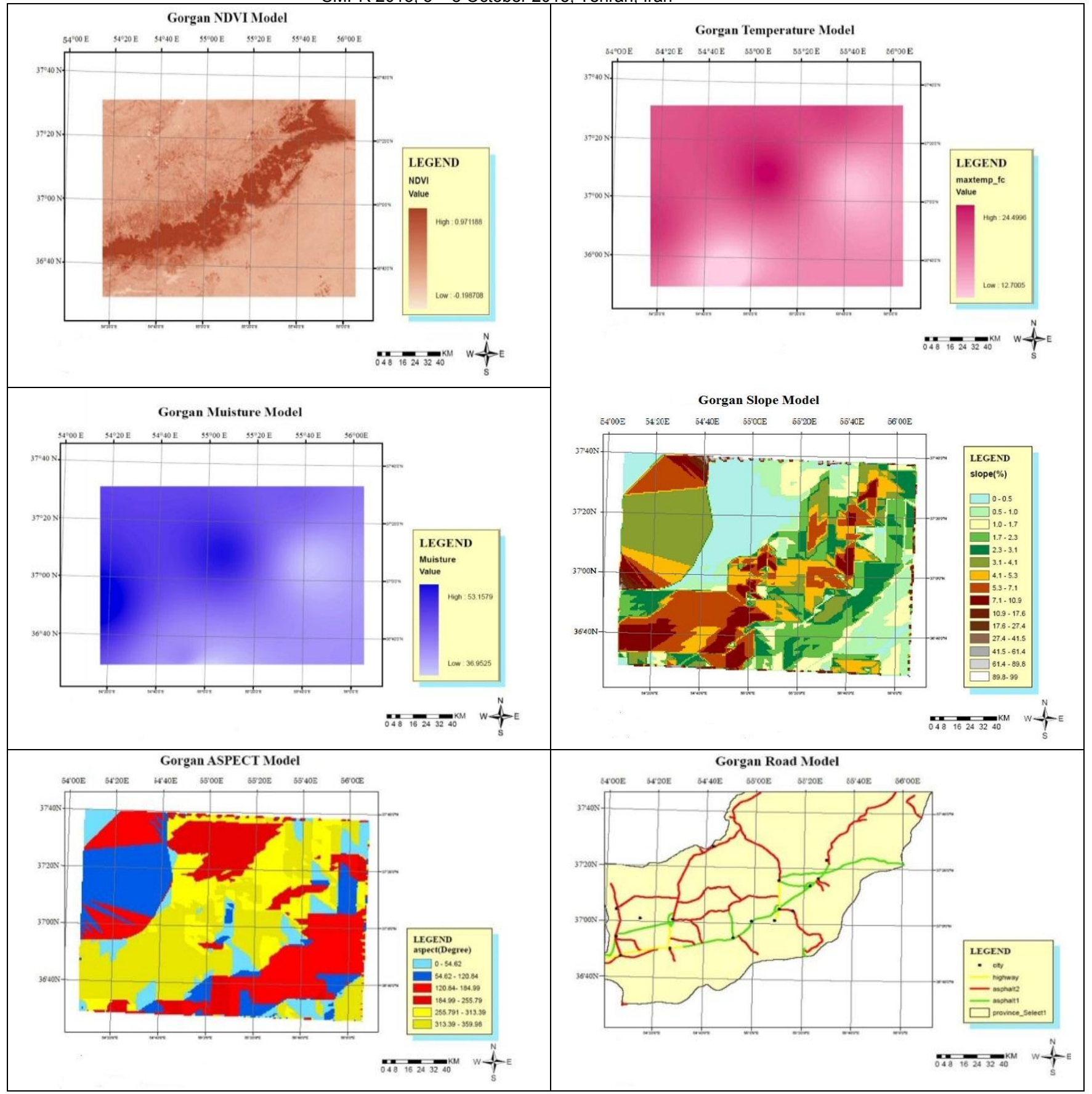

Figure 2, Thematic maps of forest fire criteria

\begin{tabular}{|c|c|c|c|c|c|c|c|}
\hline Pixel & NDVI & Maxtemp & Moisture & Slope & Aspect & DFR & Class \\
\hline P1 $\left(54^{\circ} 20^{\prime}, 37^{\circ} 20^{\prime}\right)$ & low & med & med & med & med & high & 2 \\
\hline P2 $\left(55^{\circ} 00^{\prime}, 37^{\circ} 20^{\prime}\right)$ & med & high & high & low & high & low & 3 \\
\hline P3 $\left(55^{\circ} 40^{\prime}, 37^{\circ} 20^{\prime}\right)$ & high & med & med & high & low & low & 4 \\
\hline P4 $\left(54^{\circ} 20^{\prime}, 37^{\circ} 00^{\prime}\right)$ & low & high & high & high & high & low & 3 \\
\hline P5 $\left(55^{\circ} 00^{\prime}, 37^{\circ} 00^{\prime}\right)$ & high & high & high & high & med & low & 5 \\
\hline P6 $\left(55^{\circ} 40^{\prime}, 37^{\circ} 00^{\prime}\right)$ & low & low & low & high & low & high & 2 \\
\hline P7 $\left(54^{\circ} 20^{\prime}, 36^{\circ} 40^{\prime}\right)$ & high & med & med & high & low & high & 4 \\
\hline P8 $\left(55^{\circ} 20^{\prime}, 36^{\circ} 40^{\prime}\right)$ & low & low & low & med & med & high & 1 \\
\hline P9 $\left(55^{\circ} 40^{\prime}, 36^{\circ} 40^{\prime}\right)$ & med & med & low & low & high & high & 2 \\
\hline P10 $\left(56^{\circ} 00^{\prime}, 37^{\circ} 00\right)$ & low & med & low & low & high & high & 2 \\
\hline
\end{tabular}

Table1, Information table of training data. 
In information table, each cell represents value of one criteria to one special pixel. Each pixel has classified to one class of class 1 to class6. Class1 has low low, class2 has high low, class3 has low medium, class 4 has high medium and class 5 has high forest fire potential. The granular computation of these 10 pixels done and rule has been extracted. Considering the high value of computation we just represent the output. (Granular Decision Tree)

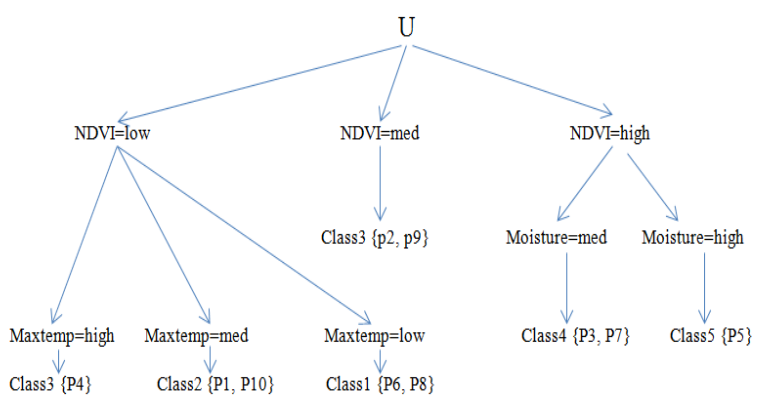

Figure 3, Granular Decision Tree

Seven rules have been extracted from information tables. The rules and their precision are listed below:

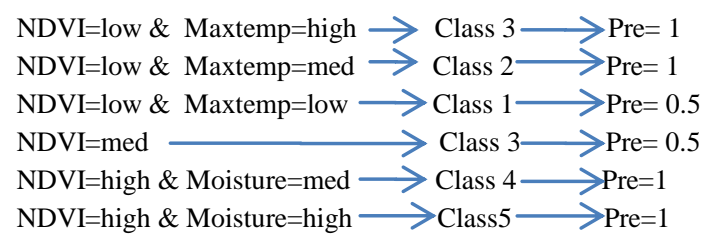

The granular computing and rule extraction of 100 training pixel are done as done for 10 sample pixels. The rules are generalized to all pixels, pixels are classified and area with high potential is determined.

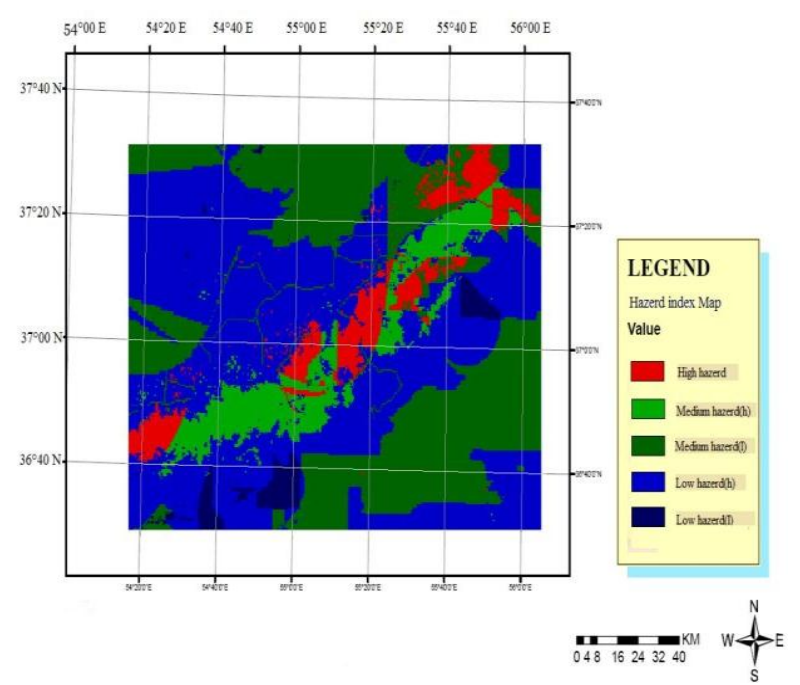

Figure4, The zoning map of Gulestan forest fire potential

According to Figure4, most pixel are arranged in class 2 with high low hazard and the least pixels are in class 1 with low low hazard. By the comparison of red pixels of MODIS fire image of Gulestan forest in 2010 and (the pixels which have high potential) and the classifications are done in his research we realize the pixel with high potential are classified at $64 \%$ precision.

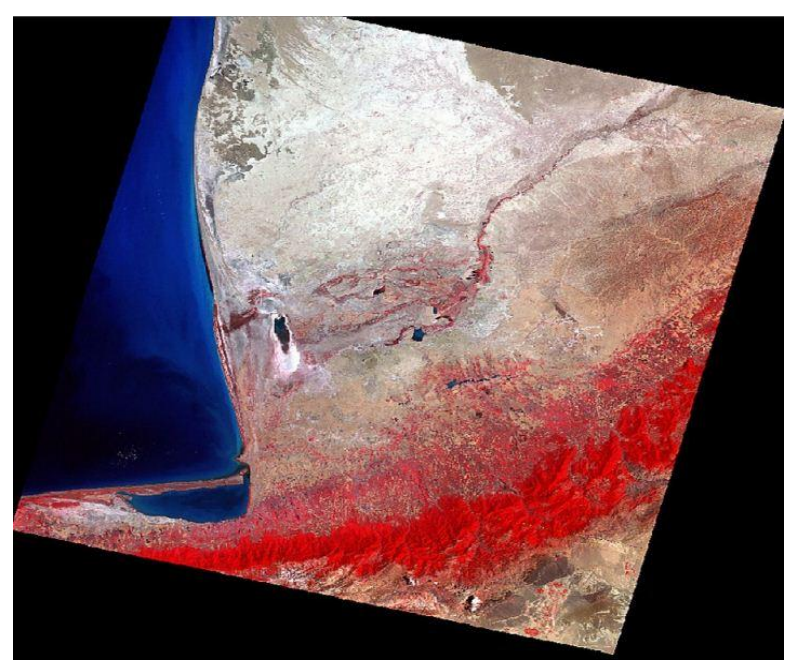

Figure 5, MODIS image of Gulestan forest fire, red pixel has high potential of fir

\section{CONCLUSION}

The most prevalent vegetation in north of Iran is forest vegetation. These forests are always threatened by natural forest fires causing economical, social and environmental damages. The causes of forest fires could be categorized as either Human or Natural Causes. Naturally, it is impossible to completely contain forest fires; however, areas with high potentials of fire could be designated and analyzed to decrease the risk of fire. The zoning of forest fire potential is a multi-criteria problem always accompanied by inherent uncertainty like other multicriteria problems. There are many algorithms for resolving Multi-Criteria problems. The algorithm used in this article is granular computing that is part of granular mathematic, also 6 criteria is considered based on experts opinions, and the area with high fire potential are classified at $64 \%$ precision.

\section{REFRENCES}

Gu, Y., Brown, J.F., Verdin, J.P., Wardlow, B., 2007. A fiveyear analysis of MODIS NDVI and NDWI for grassland drought assessment over the central Great Plains of the United States. Geophysical Research Letters, 34, L06407

Justice, C.O., Kaufman, Y.J., 2003. An enhanced contextual fire detection algorithm for MODIS. Remote Sensing of Environment 87, 273-282.

Zadeh, L.A., Gupta, M., Ragade, R., Yager, R., 1979. Fuzzy sets and information granularity, in: (Eds.), Advances in Fuzzy 
Set Theory and Application, North-Holland, Amsterdam, 1979, pp. 3-18

Morisette, J.T., Giglio, L., Csiszar, I., Setzer, A., Schroeder, W., Morton, D., Justice, C.O., 2005. Validation of MODIS active fire detection products derived from two algorithms. Earth Interactions 9, 1-23.

Samadi Alinia, H., Delavar, M.R., 2011. Tehran's seismic vulnerability classification using granular computing approach, Società Italiana di Fotogrammetria e Topografia (SIFET)

Wang, W., Qu, J.J., Liu, Y., Hao, X., Sommers, W., 2007. An improved algorithm for small and cool fire detection using MODIS data: a preliminary study in the southeastern United States. Remote Sensing of Environment 108(2), 163-170

Yao, Y.Y., 2001a. Modelling data mining with granular computing, Proceedings of COMPSA, 638-643

Yao, Y.Y., 2004b. Granular computing, Computer Science (Ji Suan Ji Ke Xue), Proceedings of th 4th Chinese National Conference on Rough Sets and Soft Computing, 31, 1-5. 